\title{
Review
}

\section{miRNAs as Regulators of Antidiabetic Effects of Fucoidans}

\author{
Chao Zhao ${ }^{1}$, Shanshan Lai ${ }^{1,2}$, Desheng Wu ${ }^{1}$, Dan Liu' ${ }^{1}$, Xiaobo Zou ${ }^{3}$, Amin Ismail ${ }^{4,5}$, Hesham El-Seedi ${ }^{6}$, \\ Randolph R.J. Arroo ${ }^{7}$, Jianbo Xiao, ${ }^{8,}$ \\ ${ }^{1}$ College of Food Science, Fujian Agriculture and Forestry University, Fuzhou 350002, China \\ ${ }^{2}$ School of Food Science and Engineering, South China University of Technology, Guangzhou 510641, China \\ ${ }^{3}$ College of Food and Biological Engineering, Jiangsu University, Zhenjiang 212013, China \\ ${ }^{4}$ Faculty of Medicine and Health Sciences, Universiti Putra Malaysia, Serdang 43400, Selangor, Malaysia \\ ${ }^{5}$ Halal Products Research Institute, Putra Infoport, Universiti Putra Malaysia, Serdang, Selangor 43400, Malaysia \\ ${ }^{6}$ Department of Medicinal Chemistry, Uppsala University, Biomedical Centre, Box 574, SE-75 123, Uppsala, Sweden \\ ${ }^{7}$ De Montfort University, Leicester School of Pharmacy, the Gateway, Leicester LE1 9BH, UK \\ ${ }^{8}$ Institute of Chinese Medical Sciences, State Key Laboratory of Quality Research in Chinese Medicine, University of Macau, Macau
}

\section{ARTICLE INFO}

Article History

Received 01 July 2019

Accepted 21 August 2019

Keywords

Diabetes mellitus

miRNAs

fucoidan

antidiabetic effects

sulfated polysaccharides

\begin{abstract}
Diabetes mellitus is a metabolic disease with a high mortality rate worldwide. MicroRNAs (miRNAs), and other small noncoding RNAs, serve as endogenous gene regulators through binding to specific sequences in RNA and modifying gene expression toward up- or down-regulation. miRNAs have become compelling therapeutic targets and play crucial roles in regulating the process of insulin resistance. Fucoidan has shown potential function as an $\alpha$-amylase inhibitor, which may be beneficial in the management of type 2 diabetes mellitus. In recent years, many studies on fucoidan focused on the decrease in blood glucose levels caused by ingesting low-glucose food or glucose-lowering components. However, the importance of miRNAs as regulators of antidiabetic effects was rarely recognized. Hence, this review emphasizes the antidiabetic mechanisms of fucoidan through regulation of miRNAs. Fucoidan exerts a vital antidiabetic effect by regulation of miRNA expression and thus provides a novel biological target for future research.
\end{abstract}

(C) 2019 International Association of Dietetic Nutrition and Safety. Publishing services by Atlantis Press International B.V. This is an open access article distributed under the CC BY-NC 4.0 license (http://creativecommons.org/licenses/by-nc/4.0/).

\section{INTRODUCTION}

Diabetes is one of the most common metabolic disorders in the world and the prevalence of diabetes has been increasing in the last 50 years [1,2]. As of 2013, there were 382 million people with diabetes worldwide, and this number is expected to rise to 592 million by 2035 [3]. Type 2 diabetes mellitus (T2DM), named non-insulindependent diabetes mellitus, is a disease characterized by insulin resistance (IR) and impaired pancreatic $\beta$-cell function that affects more than 170 million people worldwide $[4,5]$. Sustained hyperglycemia is the main diagnostic trait of this disease. People with T2DM are at increased risk for serious health problems, including cardiovascular disease, premature death, blindness, kidney failure, amputations, fractures, frailty, depression, and cognitive decline [6]. The mortality rate is almost double that of persons without the disorder [7]. T2DM needs to be recognized as a serious problem, and research into the best ways to prevent or treat this disorder needs urgent attention.

MicroRNAs (miRNAs) are a class of noncoding RNAs about 22 nucleotides in length [8]. They play crucial roles in regulation of developmental processes, cell differentiation, cell proliferation, and apoptosis pathways through interference with gene translation by sequence-specific binding to protein-coding mRNAs $[9,10]$.

“Corresponding author. Email: jianboxiao@yahoo.com

Peer review under responsibility of the International Association of Dietetic Nutrition and Safety
In recent years, miRNAs have been widely used in therapeutics of complex diseases researches, such as diabetes. Glycans were confirmed to affect the levels of target miRNAs, which offered the new strategies and approaches to deal with the challenge of T2DM.

Fucoidans consist of a series of sulfated fucose-rich polysaccharides that are mainly derived from various species of brown seaweed [11]. It is a type of complex and heterogeneous sulfated polysaccharide, consisting of L-fucose and sulfate ester groups [12-14]. However, there are only few reports about miRNAs as regulators of the antidiabetic effects of fucoidan. Herein, this review summarized the antidiabetic mechanisms of fucoidan by focusing on regulating miRNAs.

\section{TYPE 2 DIABETES MELLITUS}

The pathogenesis involves abnormalities in insulin action, insulin secretion, and endogenous glucose output. IR represents the key role in the pathogenesis of T2DM [15]. It causes multiple deleterious effects to contribute to diabetes-related complications and is defined as the impaired sensitivity of tissues, such as liver, skeletal muscle, and adipose tissues. Up till now, the major mechanisms of inducing IR by destroying the insulin signaling cascade have been identified.

Fucoidan was regarded as a crucial glucose regulator that could act on genes and enzymes existing on mitochondria, nucleus, endoplasmic reticulum (ER), and cell membrane. A fucoidan-blocked 
mitochondrial pathway was discovered on a T2DM or inflammatory cells, on which fucoidan were found to be able to decrease the level of tumor necrosis factor- $\alpha$ (TNF- $\alpha$ ) and Bid, which were crucial factors to promote mitochondrial effete pathways. The activated TNF$\alpha$ would trigger the activity of c-Jun N-terminal protein kinase and caspase. The Bid promote the Bax concentrate on the membrane of mitochondria in the form of homodimer to change the mitochondrial membrane. Thus, the cytochrome $c$, a key gene determining the $\beta$-cell apoptosis, was delivered out of the mitochondria to injure the $\beta$-cell via facilitating the activity of caspases 3 and 9 [16]. What's more, the fucoidan could restore the insulin synthesis of $\beta$-cell via Sirt-1-dependent signaling pathway. It could promote the glucagon-like peptide-1 (GLP-1) and GLP-1 receptor combining on the surface of $\beta$-cell to ameliorate its death. Then, the phosphorylation of GAPDH was activated by the combination to elevate the Sirt-1 activity. Sirt-1 plays a crucial role in insulin secretion, which can promote the activity of phosphorylation of protein kinase B (AKT) and forkhead box protein A2 (FOXA2). AKT could inhibit the phosphorylation of FOX O1 and pancreatic and duodenal homeobox-1 (PDX-1), thus together with FOXA2 activating PDX-1 to promote insulin production [17]. The adenosine monophosphate-activated protein kinase (AMPK) pathway induced by ER stress could be ameliorated by fucoidan, thus maintain glucose homeostasis. It is reported that fucoidan could promote the activity of liver kinase B1 and AKT, which could activate the phosphorylation of downstream substance AKT, which control the glucose uptake and metabolism by activating AMPK. Then the silence of mechanistic target of rapamycin complex 1 (mTORC1) (a tumor suppressor) caused by AMPK could increase the insulin receptor substance (IRS) level to promote glucose metabolism [18]. In addition, fucoidan could stimulate insulin release from $\beta$-cell through cyclic AMP (cAMP) pathway. It was found that fucoidan could act on the upstream substance of cAMP, the activation of adenylyl cyclase, and the silence of phosphodiesterase would control the breakdown of cAMP. cAMP plays a vital role in controlling the release of insulin through regulating the concentration of $\mathrm{Ca}^{2+}$ on both sides of cell membrane (Figure 1).

Insulin is secreted by the $\beta$-cells, stimulating the tyrosine kinase activity and subsequently phosphorylating various intracellular substrates, including IRS-1 and IRS-2. Phosphorylated IRS-1 and IRS-2

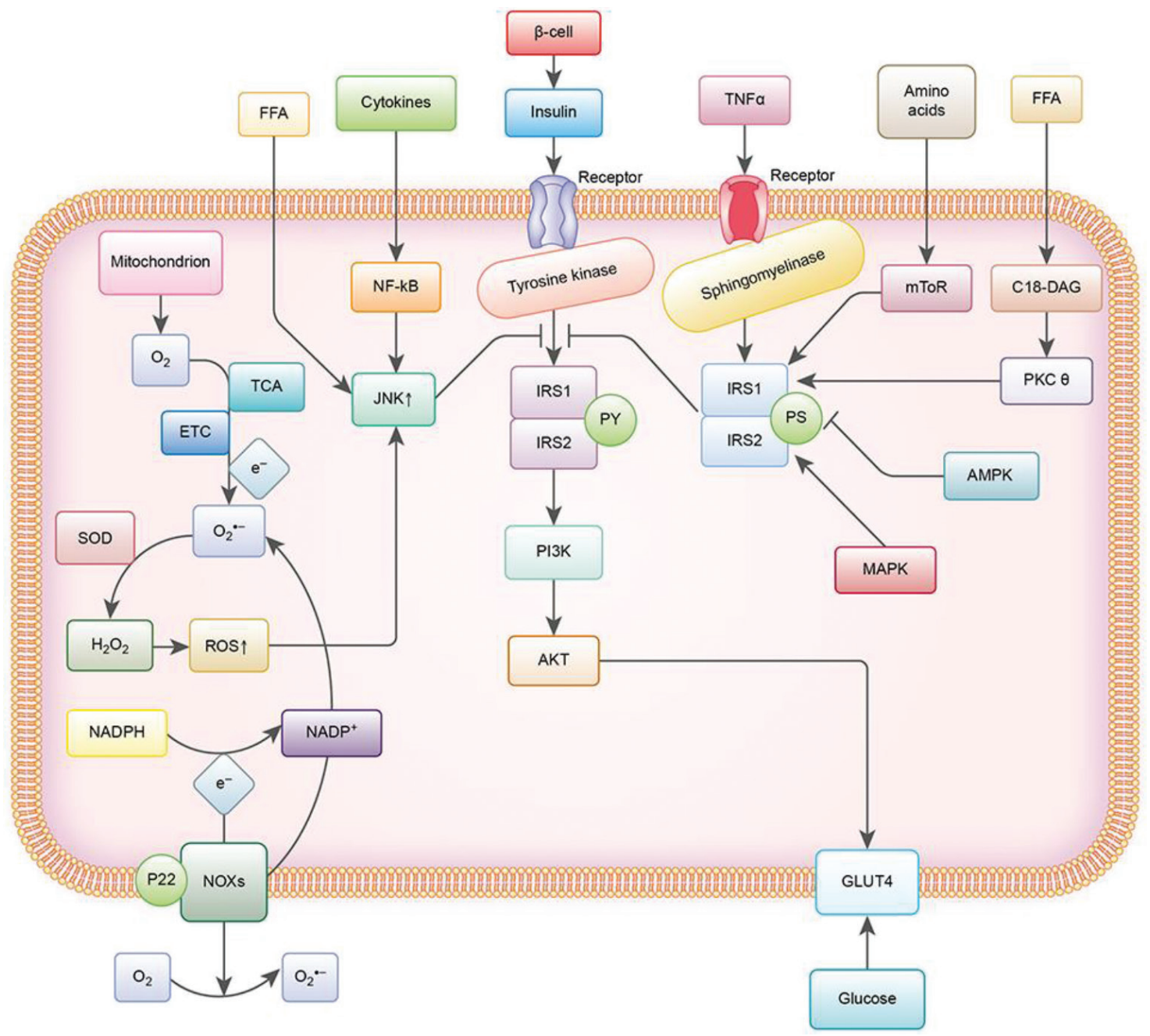

Figure 1 This flow chart summarizes the mechanisms of IR. Y, tyrosine; S, serine; IRS-1/2, substrate 1/2 of the insulin receptor; PI3K, phosphoinositide kinase 3; TNF- $\alpha$, tumor necrosis factor- $\alpha$; GLUT4, glucose transporter 4; JNK, c-Jun-N terminal kinase pathway; FFA, free fatty acids; ROS, Reactive oxygen species; NF- $\kappa \mathrm{B}$, nuclear factor kappa-light-chain enhancer of activated B cells; AKT, phosphorylation of protein kinase B; TCA, tricarboxylic acid cycle; ETC, electron transport chain; SOD, superoxide dismutase enzymes; P22, membrane partner protein; NOXs, NADPH oxidases; MAPK, mitogen-activated protein kinase; mToR, mechanistic target of rapamycin complex; PKC- $\theta$, protein kinase $\mathrm{C}$ theta; AMPK, Adenosine monophosphate activated protein kinase. 
trigger the insulin signal via activation of phosphatidylinositol-4,5-bisphosphate 3-kinase-protein kinase B (PI3K-AKT). There are several pathways that can induce IR [19]. First, excessive availability of lipids causes translocation of protein kinase C- $\theta$ (PKC- $\theta)$, and high concentrations of amino acids cause activation of the rapamycin-sensitive mTOR pathway, thus inducing serine phosphorylation of IRS-1. Besides, TNF- $\alpha$ changes the insulin receptor signaling pathways by diverting IRS-1 away via sphingomyelinases. The JNKs, which are activated by circulating cytokines and free fatty acids, can also directly inhibit phosphorylation of IRS-1 and can contribute to chronic IR. Reactive oxygen species (ROS) are by-products of oxygen consumption and cellular metabolism, which are formed by partial reduction of molecular oxygen. Nicotinamide adenine dinucleotide phosphate (NADPH) oxidases and mitochondria are two major contributors of ROS. They have been associated with IR and directly interfere with insulin signaling. Hyperglycemia, the hallmark metabolic abnormality associated with T2DM, is the key point in the treatment of diabetes. Recently, therapies directed at other coincident features, such as obesity and IR, have also been a major focus of research and therapy [20]. Food and the functional components rich in phytochemicals, such as polyphenols, polysaccharides, oligosaccharides, and so on, can be very effective antidiabetic agents [15,21-25].

\section{FUCOIDANS}

Fucoidans are commonly sulfated marine polysaccharides and have wide spectrum of bioactivities [11,22]. They are constituents of several species of brown seaweed and some marine invertebrates (such as sea urchins and cucumbers). Fucoidans were first isolated by Kylin [26] from brown algae: Ascophyllum nodosum, Fucus vesiculosus, Laminaria digitata, and Laminaria saccharina. Since then, fucoidans have been identified in more than 70 species of brown algae (Phaeophyceae), in the body wall of some marine invertebrates such as sea cucumber (Holothuroidae), and in the egg jelly coat of sea urchins (Echinoidea) [27]. Ecklonia cava, F. vesiculosus, and Cladosiphon okamuranus were most widely studied species for fucoidans [28]. Polysaccharides have distinct functional properties that are influenced by their structures. Fucoidans are a group of fucans, i.e., sulfated polysaccharides extracted from brown seaweeds and are characterized by fucose-rich sulfated groups. Other examples of fucans are ascophyllans (xylofucoglycuronan and xylofucomanuronan) and sargassans (glycuronofucogalactan). The position of sulfate groups has great influence on the beneficial biological activities of marine sulfated polysaccharides. The bioactive properties of fucoidans extracted from different species of seaweed depend on their compositional structure, charge density, distribution, and bonding of the sulfate substitutions [29]. Most of fucoidans have complex chemical compositions. Except for fucose and sulfate, they contain monosaccharide-, glucuronic acid-, and acetyl-groups, which can make structural analysis quite complex. Fucoidans extracted from different species of brown seaweed and by different methods showed a great variety in structures. Ponce et al. [30] found that fucoidan extracted at room temperature was composed mainly of L-fucose, D-galactose, and ester sulfate, yet when extracted at $70^{\circ} \mathrm{C}$, it mainly consisted of fucose, mannose, uronic acids, and low proportions of sulfate ester. Furthermore, different extraction methods (i.e., microwave-assisted extraction, conditions of pressure, extraction time, and algae/water radio) greatly affected the total fucoidan yields [31]. The molecular weights of fucoidan play a vital role in their antioxidant and anticoagulant activities [32]. Specific enzymes that degrade the fucoidans were used to simplify their structure and decrease the difficulties of analysis [33]. Several fucoidan-degrading enzymes have been isolated and characterized. Furthermore, the degradation products of fucoidans had a high potential in the medical exploitation [34]. With the development of technologies, the production of well-characterized reproducible fucoidan fractions on a commercial scale has become possible in recent years, which will make therapies from fucoidan a realizable goal [35].

In the previous few decades, the biological activities of fucoidans isolated from different marine species have been widely reported (Figure 2). They include antivirus, antitumor, immunomodulatory, anti-inflammatory, blood lipids reducing, anticoagulant, antithrombotic, antioxidant, and anti-complementary properties; also, hepatoprotective, uroprotective, and renoprotective properties

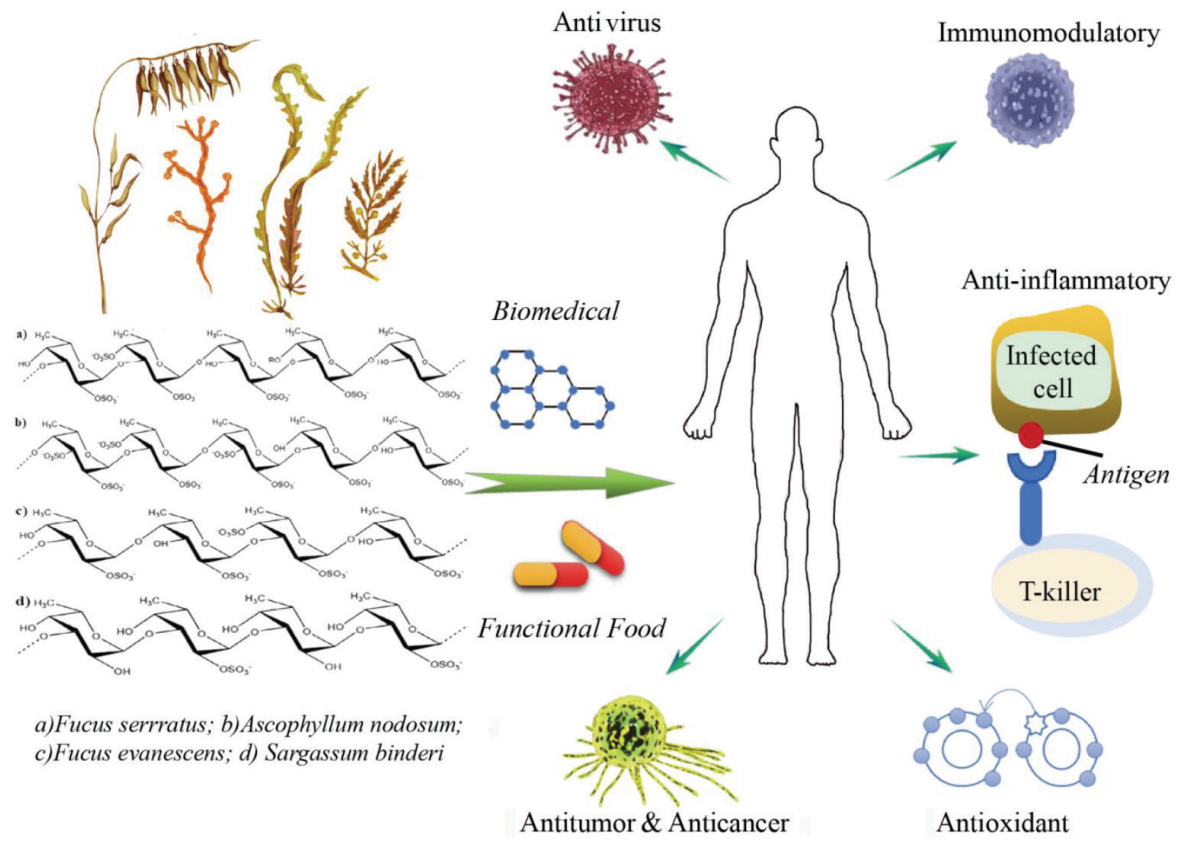

Figure $2 \mid$ Biological effects of fucoidans. The letters represent related polysaccharides, which had biological activities. 
have been recorded [36]. Compared with other polysaccharides, algal sulfated fucoidans are widely available from a variety of lowcost sources and have been investigated in recent years to develop the medical drugs or functional foods.

\section{FUCOIDANS AS ANTIDIABETIC AGENTS}

Fucoidans isolated from brown seaweeds had potential beneficial effects on diabetes. Moreover, different fucoidan demonstrated hypoglycemic effects and showed some variety in their mechanisms of action (Table 1). Fucoidans and their biological activities have been extensively studied and reported in the past 100 years. The excitement lies in the reports on success in the treatment of diabetes. Fucoidans were mainly used to treat diabetes-related complications, such as diabetic nephropathy and retinopathy. The major signaling pathways have been investigated and reported on to explain the mechanisms of antidiabetic effects of fucoidans (Figure 3).

The phenomenon has been confirmed in a range of in vitro and in vivo trials. Studies showed that fucoidans could act as $\alpha$-glucosidase inhibitors in vitro, which was associated with diabetes. What is more, the inhibitory effect of fucoidan on $\alpha$-glucosidase was largely dependent on its structure. Moreover, the structural characteristics of fucoidan were linked to the inhibition of $\alpha$-amylase. Compared with the fraction from $F$. vesiculosus, fucoidans from $A$. nodosum with their high sulfate and medium-molecular weight exhibited stronger $\alpha$-amylase inhibitory activity (Kim et al., 2015).

Fucoidan from $F$. vesiculosus decreased the fasting blood glucose and the weight of diabetic mice. Using nuclear magnetic resonance (NMR) spectroscopy, it was found that the major components were the $\alpha$-l-Fuc, $\alpha$-l-Fuc $\left(2-\mathrm{SO}_{3}^{-}\right)$, and $\alpha$-l-Fuc $\left(2,3-\mathrm{diSO}_{3}^{-}\right)$, with alternating $1 \rightarrow 3$ or $1 \rightarrow 4$ linkages [41]. In addition, fucoidans have been verified to provide pancreatic protection. Fucoidan from Acaudina molpadioides protected pancreatic islet against cell apoptosis via inhibition of inflammation in type 2 diabetic mice. Its structure has been clarified as $\left[\rightarrow 3-\alpha\right.$-L-Fucp-1 $\rightarrow 3-\alpha$-L-Fucp $2,4\left(\mathrm{OS}_{3}^{-}\right)-1 \rightarrow 3-\alpha$ L-Fuc $p-1 \rightarrow 3-\alpha$-L-Fuc $\left.2\left(\mathrm{OS}_{3}^{-}\right)-1\right]_{n}$ [16]. In streptozotocin-treated $\beta$-cells and mice, fucoidan ameliorated pancreatic $\beta$-cell death and impaired insulin synthesis via the Sirt-1-dependent pathway [17]. It might stimulate insulin secretion and provide pancreatic protection via the cAMP signaling pathway [42]. Additionally, insulin sensitivity could be enhanced by increasing the expression levels of diabetes-related genes in 3T3-L1 adipocytes [43]. Fucoidans significantly reduced blood glucose levels in diabetic mice [37]. They could decrease the FBG levels in the streptozotocin-induced diabetic rats [44]. The intake of low-molecular-weight fucoidan and fucoxanthin reduced the FBG levels [45]. Low-molecular-weight fucoidan could improve the action of insulin via AMPK stimulation [18]. Besides, obesity is strongly associated with an increased risk of T2DM and cardiovascular disease. It also showed that fucoidans could improve the IR by significantly reducing the levels of FBG, fasting insulin (FINS), total cholesterol (TC), triglyceride (TG) and low-density-lipoprotein-cholesterol (LDL-C), and increasing the contents of high-density lipoprotein-cholesterol (HDL-C) [44].

\section{MicroRNA AND T2DM}

miRNAs are synthesized by RNA polymerase II and form transcripts that fold back on themselves to form short hairpins. RNA polymerase II transcribes the long RNA precursors (pre-miRNAs) [46], processed by RNase III enzymes, such as Drosha and Dicer [47,48], and then incorporated into the RNA interference effector complex (RISCs) [49], which mediates the degradation of targeted mRNA transcripts and translational arrest, and negatively regulates gene expression at the posttranscriptional level by binding to the $3^{\prime}$-untranslated region of target RNAs [50,51] (Figure 4). Since the discovery of miRNAs in Caenorhabditis elegans, more than 28,600 miRNAs have been found in plants, animals, and viruses [52]. About one-third of known miRNAs were embedded within introns of protein-coding genes. They are co-transcribed with their host genes, which make that miRNA and protein expression are regulated in a coordinated fashion [53]. From studies of miRNAs functions in cancer cells, many of the functional roles have shown the involvement of miRNAs in human diseases [46]. Almost $60 \%$ of human protein-coding genes were potentially regulated by miRNAs in health and disease [54]. Mechanisms involving miRNAs in disease processes are very complex; some diseases

Table 1 The trials of fucoidans linked to diabetes mellitus

\begin{tabular}{|c|c|c|c|}
\hline Sources & Structures & Mechanisms & References \\
\hline Undaria pinnatifida & $\begin{array}{l}\text { L-Fucose together with xylose, galactose, and } \\
\text { mannose }\end{array}$ & Improve insulin sensitivity & Kim et al. [37] \\
\hline Acaudina molpadioides & $\begin{array}{l}{\left[\rightarrow 3-\alpha \text {-L-Fucp- } 1 \rightarrow 3-\alpha \text {-L-Fucp } 2,4\left(\mathrm{OS}_{3}^{-}\right)-1 \rightarrow 3-\alpha-\right.} \\
\left.\quad \mathrm{L}-\mathrm{Fu} c p-1 \rightarrow 3-\alpha-\mathrm{L}-\mathrm{Fu} c p 2\left(\mathrm{OS}_{3}^{-}\right)-1\right]_{n}\end{array}$ & $\begin{array}{l}\text { Blocked mitochondrial pathway in } \\
\text { pancreatic islet cell apoptosis via } \\
\text { regulation of inflammatory cytokines }\end{array}$ & Wang et al. [16] \\
\hline Ascophyllum nodosum & $\begin{array}{l}\alpha-(1-3) \text { linked fucose with a low proportion of } \alpha-(1-4) \\
\text { linked fucose or a repeating } \alpha-(1-3) \text { and } \alpha-(1-4) \text {-link- } \\
\text { age }\end{array}$ & Inhibit $\alpha$-amylase activity & Kim et al. [38] \\
\hline Turbinaria ornata & $\begin{array}{l}\text { Presence of alkane proton in two methyl group, alkyl at } \\
\text { sulfonyl attached proton, methoxy attached proton at } \\
\mathrm{H}-4 \text {, present 3-linked D-galactopyranosyl, a terminal } \\
\alpha \text {-L-fucose, 3-linked } \alpha \text {-L-fucose, and } \\
\text { 3,4 distribution of } \alpha \text {-L-fucose. }\end{array}$ & Inhibit $\alpha$-amylase activity & Lakshmanasenthil et al. [39] \\
\hline Sargassum wightii & $\begin{array}{l}\text { Presence of alkane proton in two methyl group, alkyl at } \\
\text { sulfonyl attached proton, methoxy attached proton at } \\
\mathrm{H} \text {-4, present 3-linked D-galactopyranosyl, a terminal } \\
\alpha \text {-L-fucose, 3-linked } \alpha \text {-L-fucose and } \\
\text { 3,4 distribution of } \alpha \text {-L-fucose. }\end{array}$ & Inhibit $\alpha$-D-glucosidase & Kumar et al. [40] \\
\hline
\end{tabular}



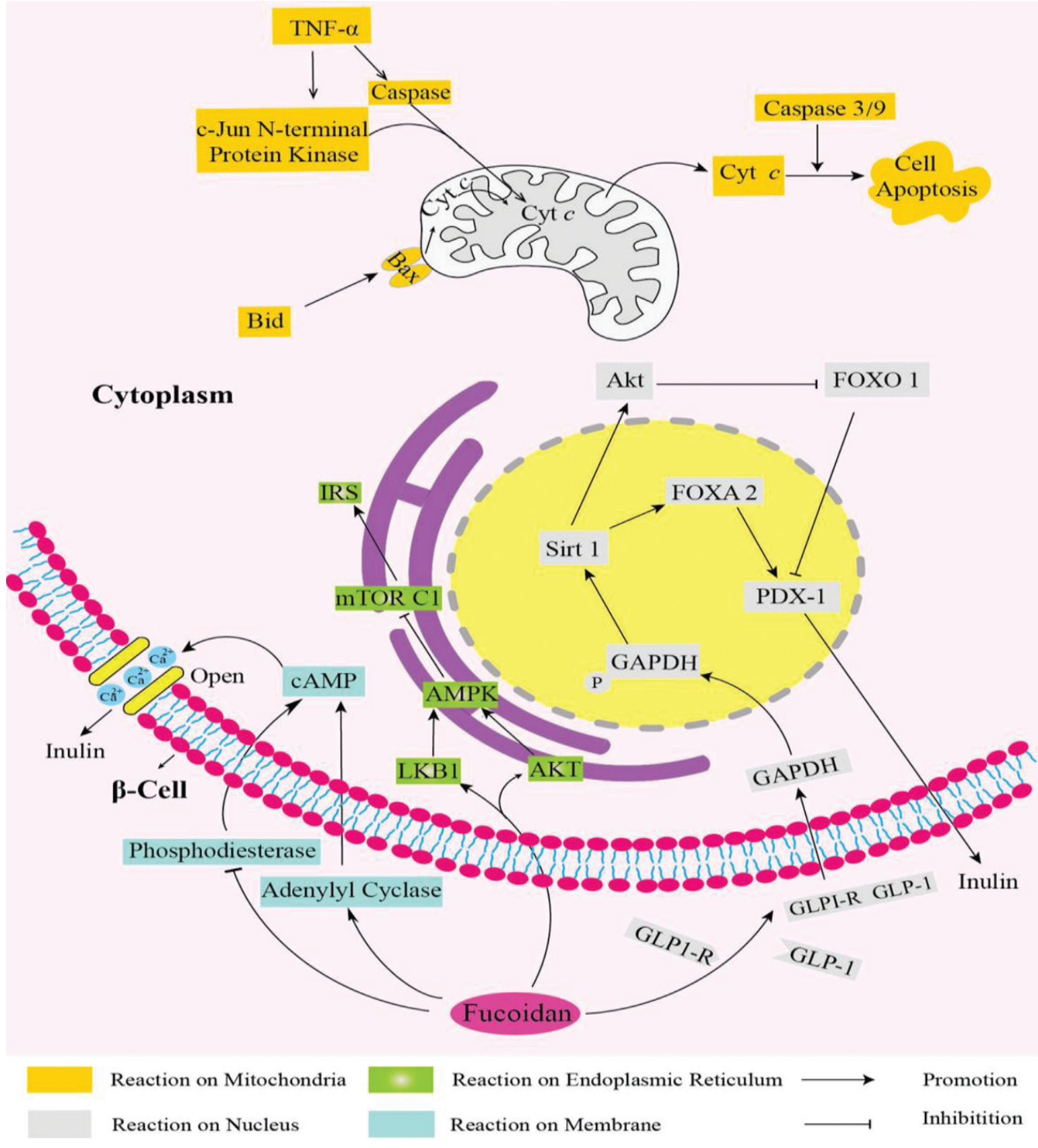

Figure 3 Main signaling pathways recruited to adjust the blood glucose.

were even associated with more than 20 miRNAs. Currently, with the development of investigation, an increasing number of researchers have focused on the relationship between diabetes and miRNAs.

There is no doubt that miRNAs will directly or indirectly affect our health. Abnormal expression of miRNAs was observed in plasma, serum, and whole blood in patients with T2DM [55-58]. By using microarray screening and miRNA network inference, target miRNAs, i.e., miR-15a, miR-20b, miR-21, miR-24, miR-126, miR-191, miR-197, miR-223, miR320, and miR-486 levels were lowered, while miR-28-3p expression was increased in plasma of diabetic patients. When levels of serum miRNA in newly diagnosed patients with T2DM and prediabetes or susceptible individuals were measured, serum levels of miR-9, miR-29a, miR-30d,
miR34a, miR-124a, miR-146a, and miR-375 levels in T2DM patients were significantly higher than those in susceptable people. When compared with prediabetic individuals, patients with T2DM had serum levels of miR-9, miR-29a, miR-34a, miR-146a, and miR-375, which were significantly upregulated in T2DM patients. However, there were no significant differences in the expression of miRNAs between prediabetic patients and susceptible individuals [56]. There have also been reports that abnormal expression of miRNAs was found in the whole blood and exosome of the metabolic syndrome population [55]. Among patients with T2DM, miR-27a, miR150, miR-192, miR-320a, and miR-375 were upregulated, and then the increase levels of miR-27a and miR-320a were associated with higher FBG. Moreover, obesity also could influence the expression of miRNAs in patients with diabetes. Meanwhile, 


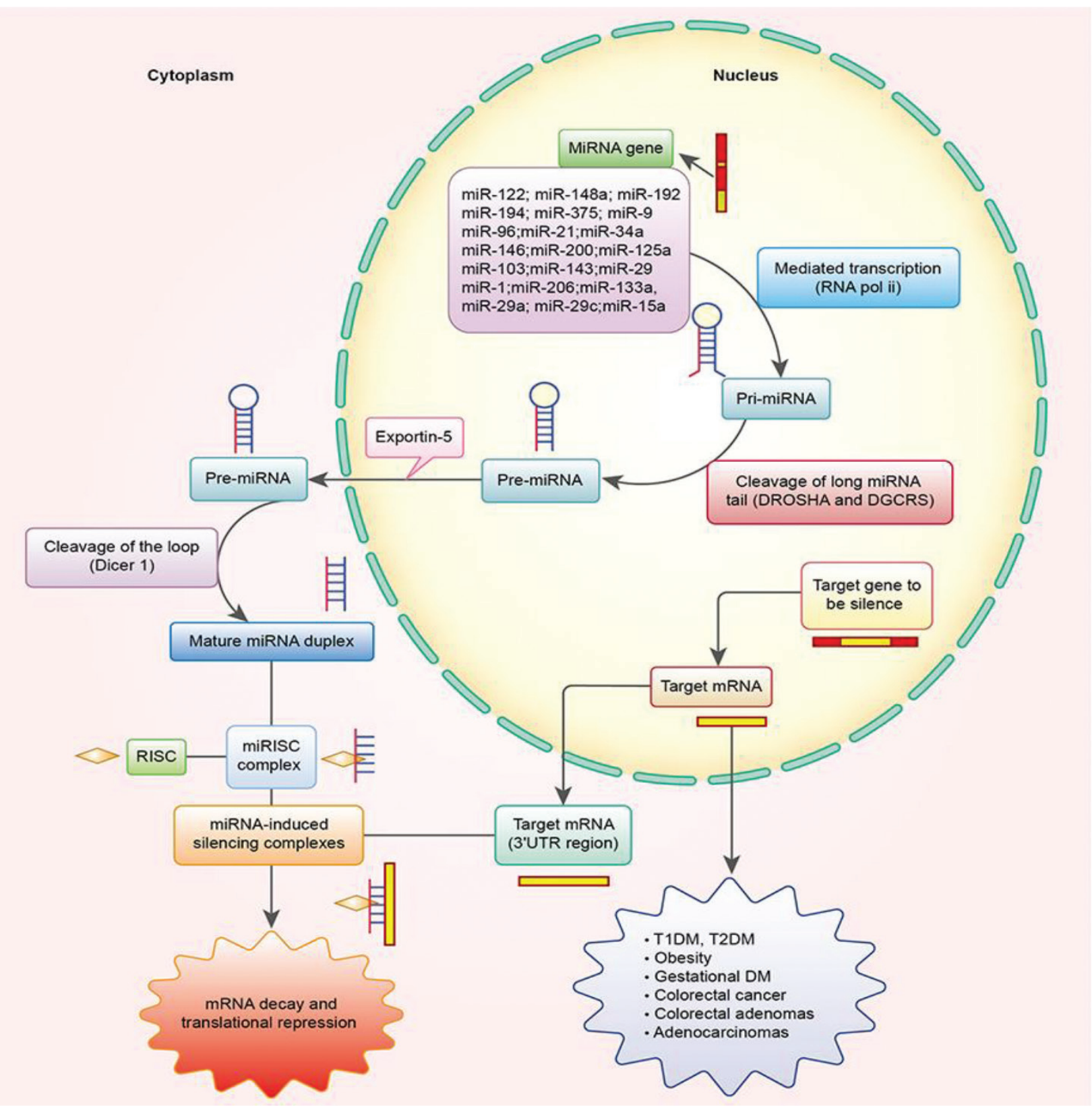

Figure 4 A schematic diagram of miRNA synthesis. RNA polymerase II transcribes the long RNA precursors (pri-miRNAs) and processed by Drosha and Dicer and incorporated into the RNA interference effector complex, which mediate degradation of targeted mRNA transcripts and translational arrest, negatively regulate gene expression at the posttranscriptional level by binding to the $3^{\prime}$-untranslated region of target RNAs.

aberrant patterns of expression of miRNAs were observed in adipocytes [59,60].

MiRNAs play a key role in the pancreas $[61,62]$, where they regulate insulin production and insulin secretion in $\beta$-cells of the pancreatic islets [63,64]. MiR-375 was important for normal pancreatic islet formation and had many effects on islet $\beta$-cells, including insulin expression and secretion, islet $\beta$-cell proliferation. MiR-375 directly reduced PDK-1 protein levels, which in turn led to a decreased glucose stimulation that otherwise would have initiated expression of the insulin gene and DNA synthesis in $\beta$-cells [65].

Consistent with the above evidence, the overexpression of miR-30d inhibited the insulin gene expression, which was related to the deficiency of insulin synthesis in diabetic patients [66]. The early inflammatory factors of diabetes mellitus type 1 interfere with insulin secretion and destroy islet $\beta$-cells. This process coincides with abnormal expression levels of miR-21, miR-34a, and miR146 [67-69]. Meanwhile, the activation of p53 pathway induced by palmitic acid (PA) was shown to lead to the up-regulation of miR-34a and miR-146 levels, resulting in the pancreatic $\beta$-cell apoptosis and the decrease of nutrient-induced insulin secretion [70-73].

More recently, elegant investigations have validated the hypothesis that miRNAs are implicated in the target tissue for insulin. Herrera et al. [63] reported that the presence of 283 DMT2-related miRNAs in adipose, liver, and muscle tissues by comparing microarrays from hyperglycemic, intermediate glycemic, and normoglycemic rats. They identified 29 miRNAs that showed significant differences, nine in adipose tissue, 18 in liver, and two in muscle. The expres- 
sion patterns of five miRNAs were associated with the strain-specific glycemic phenotype. MiR-222/miR-27a and miR-195/miR-103 were upregulated in adipose tissue and liver, respectively, while miR-10b was downregulated in muscle. Likewise, He et al. [74] suggested that three paralogs of the miR-29 family were upregulated in muscle, fat tissue, and liver of diabetic rats. Overexpression of the miR-29 family in 3T3-L1 adipocytes reduced the glucose uptake of insulin stimulation. Compared with non-insulin-stimulated, it was found that miR$29 \mathrm{a}$ and miR-29c were highly expressed in insulin sensitive tissues $[75,76]$. Taken together, these reports have revealed the crucial roles of miRNAs in the etiology of type 2 diabetes.

\section{MIRNA-TARGETED MODULATION BY FUCOIDANS}

Dietary phytochemicals have been used to change metabolism and alter diseases progression and clinical outcomes [77]. Polysaccharides or oligosaccharides from marine seaweed or resources are known to affect the levels of miRNAs. Alginate oligosaccharide or fucoidan can regulate the levels of miR-29b, miR-29c, and miR-17-5p [78-80]. In subjects with metabolic syndrome, specifically obesity, prediabetes, and T2DM, a large amount of miRNAs are deregulated, e.g. miR-21, miR-24.1, miR-27a, miR-28-3p, miR-29b, miR-30d, miR-34a, miR-93, miR-126, miR-146a, miR-148, miR-150, miR-155, and miR-223. These miRNAs significantly changed across the diabetes spectrum and were associated with measures of pancreatic islet $\beta$-cell function and glycemic control [81]. The miR-29 family has emerged as important regulators of glucose metabolism. It was among the most abundantly expressed miRNAs in the pancreas and liver and showed strong regulatory functions in obesity and diabetes [76]. The miR-29 family of miRNAs in humans comprises three mature members, miR-29a, miR29b, and miR-29c. MiR-29 has been shown to affect glucose metabolism, lipid metabolism, and insulin responsiveness in skeletal muscle, while both miR-29a and miR-29c could regulate glucose uptake and insulinstimulated glucose metabolism [82]. Chen et al. [83] have reported that miR-29b inhibits progressive renal inflammation and fibrosis in type 2 diabetes in $d b / d b$ mice. Under diabetic conditions, miR-29b was largely downregulated in response to advanced glycation end product. Besides, Zhu et al. [84] have revealed 32 miRNAs that were differentially expressed in gestational diabetes mellitus, including five upregulated miRNAs (hsa-miR-16-5p, hsa-miR-17-5p, hsa-miR19a-3p, hsa-miR-19b-3p, and hsa-miR-20a-5p). These miRNAs may serve as noninvasive biomarkers. Moreover, reduction of miR-17-5p and upregulation of miR-29b-3p directly regulated circadian gene expression in the maturing islet cells of 10-day-old rats [85].

Until now, many studies have focused on miRNA-targeted modulation of fucoidan against human diseases. Wu et al. [78] showed that fucoidan inhibited breast cancer progression by dual regulation of the miR-29c/ADAM-12 and miR-17-5p/PTEN axes. Furthermore, fucoidan has been confirmed to markedly upregulate miR-29b in human hepatocellular carcinoma cells to regulate the DNA methyltransferase 3B-metastasis suppressor 1 (DNMT3B-MTSS1) axis and inhibit epithelial-mesenchymal transition (EMT) (increased E-cadherin and decreased N-cadherin). DNMT3B is an important downstream target of miR-29b. Induction of miR-29b results in suppression of DNMT3B and a consequent increase in MTSS1, which is usually repressed in human hepatocellular carcinoma. It was a novel target of DNMT3B [79]. Based on the reported studies, it was confirmed that fucoidan could upregulate the level of miR-29b and
miR-29c and downregulate the level of miR-17-5p, which would contribute to treatment of type 2 diabetes. At present, only limited data are available on the role of novel antidiabetic polysaccharides or oligosaccharides from algae as miRNAs regulators. This promising field should be explored further, and the fucoidan-miRNAs relationship needs to be worked out in more detail.

\section{CONCLUSION}

Fucoidan has been widely used in clinical studies and is a novel therapeutic agent with potential for the treatment of diabetes. The limitation of fucoidan was their poor bioavailability. Even though the discovery in this field is still at the infancy stage, the application of fucoidan is likely to have a bright future. There is no doubt that the regulation of miRNAs by fucoidan could create novel therapeutic strategies for hypoglycemic treatment in T2DM. However, there are still some questions that need to be addressed. Due to the lack of sufficient understanding of regulation of miRNAs by fucoidan, the related research was even more difficult. Systemic approaches toward the fucoidan on antidiabetes are almost absent. It is necessary to get more studies to focus on the antidiabetic effects of fucoidan through miRNA regulation.

\section{CONFLICTS OF INTEREST}

The authors declare they have no conflicts of interest.

\section{AUTHOR CONTRIBUTIONS}

C.Z., S.-S.L., D.-S.W. and D.L. contributed in writing-original draft preparation, X.-B.Z., A.I. and H.-E.S. contributed in writing-review and editing, J.-B.X. contributed in supervision. C.Z. contributed in funding acquisition.

\section{ACKNOWLEDGMENTS}

This work was financially supported by Project of Fuzhou Municipal Bureau of Science and Technology (2018-G-87) and Multi-Year Research Grant of University of Macau (MYRG201800169-ICMS). The project was also supported by International Science and Technology Cooperation Project (KXb16011A) of Fujian Agriculture and Forestry University and Fujian Province Key Laboratory for the Development of Bioactive Material from Marine Algae Grant (2018FZSK01).

\section{REFERENCES}

[1] Shaw JE, Sicree RA, Zimmet PZ. Global estimates of the prevalence of diabetes for 2010 and 2030. Diabetes Res Clin Pract 2010;87:4-14.

[2] Whiting DR, Guariguata L, Weil C, Shaw J. IDF diabetes atlas: global estimates of the prevalence of diabetes for 2011 and 2030 Diabetes Res Clin Pract 2011;94:311-21.

[3] Guariguata L, Whiting DR, Hambleton I, Beagley J, Linnenkamp U, Shaw JE. Global estimates of diabetes prevalence for 2013 and projections for 2035. Diabetes Res Clin Pract 2014;103:137-49. 
[4] Stumvoll M, Goldstein BJ, van Haeften TW. Type 2 diabetes: principles of pathogenesis and therapy. Lancet 2005;365:1333-46.

[5] Wild S, Roglic G, Green A, Sicree R, King H. Global prevalence of diabetes: estimates for the year 2000 and projections for 2030. Diabetes Care 2004;27:1047-53.

[6] Goff DC Jr, Gerstein HC, Ginsberg HN, Cushman WC, Margolis KL, Byington RP, et al. Prevention of cardiovascular disease in persons with type 2 diabetes mellitus: current knowledge and rationale for the Action to Control Cardiovascular Risk in Diabetes (ACCORD) trial. Am J Cardiol 2007;99:4i-20i.

[7] Gaede P, Lund-Andersen H, Parving HH, Pedersen O. Effect of a multifactorial intervention on mortality in type 2 diabetes. N Engl J Med 2008;358:580-91.

[8] Griffiths-Jones S. The microRNA Registry. Nucleic Acids Res 2004;32:D109-D11.

[9] Pogribny IP, Beland FA, Rusyn I. The role of microRNAs in the development and progression of chemical-associated cancers. Toxicol Appl Pharmacol 2016;312:3-10.

[10] Sayed D, Abdellatif M. MicroRNAs in development and disease. Physiol Rev 2011;91:827-87.

[11] Yang CF, Lai SS, Chen YH, Liu D, Liu B, Ai C, et al. Anti-diabetic effect of oligosaccharides from seaweed Sargassum confusum via JNK-IRS1/PI3K signalling pathways and regulation of gut microbiota. Food Chem Toxicol 2019;131:110562.

[12] Bilan MI, Grachev AA, Ustuzhanina NE, Shashkov AS, Nifantiev NE, Usov AI. Structure of a fucoidan from the brown seaweed Fucus evanescens C.Ag. Carbohydr Res 2002;337:719-30.

[13] Kim KJ, Lee OH, Lee BY. Fucoidan, a sulfated polysaccharide, inhibits adipogenesis through the mitogen-activated protein kinase pathway in 3T3-L1 preadipocytes. Life Sci 2010;86:791-7.

[14] Zhao C, Wu Y, Liu X, Liu B, Cao H, Yu H, et al. Functional properties, structural studies and chemo-enzymatic synthesis of oligosaccharides. Trends Food Sci Technol 2017;66:135-45.

[15] Zhao C, Yang C, Chen M, Liu B, Yi L, Cornara L, et al. Regulatory efficacy of brown seaweed Lessonia nigrescens extract on the gene expression profile and intestinal microflora in type 2 diabetic mice. Mol Nutr Food Res 2018;62:1700730.

[16] Wang J, Hu S, Wang J, Li S, Jiang W. Fucoidan from Acaudina molpadioides protects pancreatic islet against cell apoptosis via inhibition of inflammation in type 2 diabetic mice. Food Sci Biotechnol 2016;25:293-300.

[17] Yu WC, Chen YL, Hwang PA, Chen TH, Chou TC. Fucoidan ameliorates pancreatic $\beta$-cell death and impaired insulin synthesis in streptozotocin-treated $\beta$ cells and mice via a Sirt-1dependent manner. Mol Nutr Food Res 2017;61:1700136.

[18] Jeong YT, Kim YD, Jung YM, Park DC, Lee DS, Ku SK, et al. Low molecular weight fucoidan improves endoplasmic reticulum stress-reduced insulin sensitivity through AMP-activated protein kinase activation in L6 myotubes and restores lipid homeostasis in a mouse model of type 2 diabetes. Mol Pharmacol 2013;84:147-57.

[19] Chen Y, Liu D, Wang D, Lai S, Zhong R, Liu Y, et al. Hypoglycemic activity and gut microbiota regulation of a novel polysaccharide from Grifola frondosa in type 2 diabetic mice. Food Chem Toxicol 2019;126:295-302.

[20] Nathan DM, Buse JB, Davidson MB, Ferrannini E, Holman RR, Sherwin R, et al. Management of hyperglycaemia in type 2 diabetes mellitus: a consensus algorithm for the initiation and adjustment of therapy. Update regarding the thiazolidinediones. Diabetologia 2008;51:8-11.
[21] Cao H, Ou J, Chen L, Zhang Y, Szkudelski T, Delmas D, et al. Dietary polyphenols and type 2 diabetes: human study and clinical trial. Crit Rev Food Sci Nutr 2018;1-9.

[22] Zhao C, Yang C, Liu B, Lin L, Sarker SD, Nahar L, et al. Bioactive compounds from marine macroalgae and their hypoglycemic benefits. Trends Food Sci Technol 2018;72:1-12.

[23] Zhao C, Yang C, Wai STC, Zhang Y, Portillo MP, Paoli P, et al. Regulation of glucose metabolism by bioactive phytochemicals for the management of type 2 diabetes mellitus. Crit Rev Food Sci Nutr 2019;59:830-47.

[24] Zheng Y, Zhang S, Wang Q, Lu X, Lin L, Tian Y, et al. Characterization and hypoglycemic activity of a $\beta$-pyran polysaccharides from bamboo shoot (Leleba oldhami Nakal) shells. Carbohydr Polym 2016;144:438-46.

[25] Loizzo MR, Pugliese A, Bonesi M, Tenuta MC, Menichini F, Xiao J, et al. Edible flowers: a rich source of phytochemicals with antioxidant and hypoglycemic properties. J Agric Food Chem 2016;64:2467-74.

[26] Kylin H. Zur Biochemie der meeresalgen. Hoppe-Seyler's Z Physiol Chem 1913;83:171-97.

[27] Chollet L, Saboural P, Chauvierre C, Villemin JN, Letourneur D, Chaubet F. Fucoidans in nanomedicine. Mar Drugs 2016;14: 145.

[28] Wijesinghe WAJP, Jeon YJ. Biological activities and potential industrial applications of fucose rich sulfated polysaccharides and fucoidans isolated from brown seaweeds: a review. Carbohydr Polym 2012;88:13-20.

[29] Ale MT, Mikkelsen JD, Meyer AS. Important determinants for fucoidan bioactivity: a critical review of structure-function relations and extraction methods for fucose-containing sulfated polysaccharides from brown seaweeds. Mar Drugs 2011;9:2106-30.

[30] Ponce NM, Pujol CA, Damonte EB, Flores ML, Stortz CA. Fucoidans from the brown seaweed Adenocystis utricularis: extraction methods, antiviral activity and structural studies. Carbohydr Res 2003;338:153-65.

[31] Rodriguez-Jasso RM, Mussatto SI, Pastrana L, Aguilar CN, Teixeira JA. Microwave-assisted extraction of sulfated polysaccharides (fucoidan) from brown seaweed. Carbohydr Polym 2011;86:1137-44.

[32] Wang J, Zhang Q, Zhang Z, Song H, Li P. Potential antioxidant and anticoagulant capacity of low molecular weight fucoidan fractions extracted from Laminaria japonica. Int J Biol Macromol 2010;46:6-12.

[33] Kusaykin M, Bakunina I, Sova V, Ermakova S, Kuznetsova T, Besednova N, et al. Structure, biological activity, and enzymatic transformation of fucoidans from the brown seaweeds. Biotechnol J 2008;3:904-15.

[34] Holtkamp AD, Kelly S, Ulber R, Lang S. Fucoidans and fucoidanases-focus on techniques for molecular structure elucidation and modification of marine polysaccharides. Appl Microbiol Biot 2009;82:1-11.

[35] Fitton JH. Therapies from fucoidan; multifunctional marine polymers. Mar drugs 2011;9:1731-60.

[36] Li B, Lu F, Wei X, Zhao R. Fucoidan: structure and bioactivity. Molecules 2008;13:1671-95.

[37] Kim KJ, Yoon KY, Lee BY. Fucoidan regulate blood glucose homeostasis in C57BL/KSJ $\mathrm{m}+/+d b$ and C57BL/KSJ $d b / d b$ mice. Fitoterapia 2012;83:1105-9.

[38] Kim KT, Rioux LE, Turgeon SL. Molecular weight and sulfate content modulate the inhibition of $\alpha$-amylase by fucoidan relevant for type 2 diabetes management. Pharmanutrition 2015;3:108-14. 
[39] Lakshmanasenthil S, Vinothkumar T, Geetharamani D, Marudhupandi T, Suja G, Sindhu NS. Fucoidan-a novel $\alpha$-amylase inhibitor from Turbinaria ornata with relevance to NIDDM therapy. Biocatal Agric Biotechnol 2014;3:66-70.

[40] Kumar S, Sahoo D, Levine I. Assessment of nutritional value in a brown seaweed Sargassum wightii and their seasonal variations. Algal Res 2015;9:117-25.

[41] Shan X, Liu X, Hao J, Cai C, Fan F, Dun Y, et al. In vitro and in vivo hypoglycemic effects of brown algal fucoidans. Int J Biol Macromol 2016;82:249-55.

[42] Jiang X, Yu J, Ma Z, Zhang H, Xie F. Effects of fucoidan on insulin stimulation and pancreatic protection via the cAMP signaling pathway in vivo and in vitro. Mol Med Rep 2015;12:4501-7.

[43] Kim KJ, Lee OH, Lee HC, Kim YC, Lee BY. Effect of fucoidan on expression of diabetes mellitus related genes in mouse adipocytes. Food Sci Biotechnol 2007;16:212-17.

[44] Yang XD, Liu CG, Tian YJ, Gao DH, Li WS, Ma HL. Inhibitory effect of fucoidan on hypoglycemia in diabetes mellitus anim. Int J Clin Exp Med 2017;10:8529-34.

[45] Lin HV, Tsou YC, Chen YT, Lu WJ, Hwang PA. Effects of low-molecular-weight fucoidan and high stability fucoxanthin on glucose homeostasis, lipid metabolism, and liver function in a mouse model of type II diabetes. Mar Drugs 2017;15:113.

[46] Alvarez-Garcia I, Miska EA. MicroRNA functions in animal development and human disease. Development 2005;132: 4653-62.

[47] Bernstein E, Caudy AA, Hammond SM, Hannon GJ. Role for a bidentate ribonuclease in the initiation step of RNA interference. Nature 2001;409:363-6.

[48] Lee Y, Ahn C, Han J, Choi H, Kim J, Yim J, et al. The nuclear RNase III Drosha initiates microRNA processing. Nature 2003;425:415-9.

[49] He L, Thomson JM, Hemann MT, Hernando-Monge E, Mu D, Goodson S, et al. A microRNA polycistron as a potential human oncogene. Nature 2005;435:828-33.

[50] Brown RH. Medicine. A reinnervating microRNA. Science 2009;326:1494-5.

[51] Caporali A, Meloni M, Völlenkle C, Bonci D, Sala-Newby GB, Addis R, et al. Deregulation of microRNA-503 contributes to diabetes mellitus-induced impairment of endothelial function and reparative angiogenesis after limb ischemia. Circulation 2011;123:282-91.

[52] Pasquinelli AE, Ruvkun G. Control and developmental timing by microRNAs and their targets. Annu Rev Cell Dev Biol 2002;18: 495-513.

[53] Mendell JT, Olson EN. MicroRNAs in stress signaling and human disease. Cell 2012;148:1172-87.

[54] Sayed D, Abdellatif M. MicroRNAs in development and disease. Physiol Rev 2001;91:827-87.

[55] Karolina DS, Tavintharan S, Armugam A, Sepramaniam S, Pek SL, Wong MT, et al. Circulating miRNA profiles in patients with metabolic syndrome. J Clin Endocrinol Metab 2012;97:E2271-E6.

[56] Kong L, Zhu J, Han W, Jiang X, Xu M, Zhao Y, et al. Significance of serum microRNAs in pre-diabetes and newly diagnosed type 2 diabetes: a clinical study. Acta Diabetol 2011;48:61-9.

[57] Rong Y, Bao W, Shan Z, Liu J, Yu X, Xia S, et al. Increased micro RNA-146a levels in plasma of patients with newly diagnosed type 2 diabetes mellitus. PLoS One 2013;8:e73272.

[58] Zampetaki A, Kiechl S, Drozdov I, Willeit P, Mayr U, Prokopi $\mathrm{M}$, et al. Plasma microRNA profiling reveals loss of endothe- lial miR-126 and other microRNAs in type 2 diabetes. Circ Res 2010;107:810-7.

[59] Pescador N, Pérez-Barba M, Ibarra JM, Corbatón A, MartínezLarrad MT, Serrano-Ríos M. Serum circulating microRNA profiling for identification of potential type 2 diabetes and obesity biomarkers. PLoS One 2013;8:e77251.

[60] Schneeberger M, Altirriba J, García A, Esteban Y, Castaño C, GarcíaLavandeira M, et al. Deletion of miRNA processing enzyme Dicer in POMC-expressing cells leads to pituitary dysfunction, neurodegeneration and development of obesity. Mol Metab 2012;2:74-85.

[61] Kloosterman WP, Lagendijk AK, Ketting RF, Moulton JD, Plasterk RHA. Targeted inhibition of miRNA maturation with morpholinos reveals a role for miR-375 in pancreatic islet development. PLoS Biol 2007;5:e203.

[62] Latreille M, Herrmanns K, Renwick N, Tuschl T, Malecki MT, McCarthy MI, et al. miR-375 gene dosage in pancreatic $\beta$-cells: implications for regulation of $\beta$-cell mass and biomarker development. J Mol Med (Berl) 2015;93:1159-69.

[63] Herrera BM, Lockstone HE, Taylor JM, Ria M, Barrett A, Collins $\mathrm{S}$, et al. Global microRNA expression profiles in insulin target tissues in a spontaneous rat model of type 2 diabetes. Diabetologia 2010;53:1099-109.

[64] Poy MN, Eliasson L, Krutzfeldt J, Kuwajima S, Ma X, MacDonald $\mathrm{PE}$, et al. A pancreatic islet-specific microRNA regulates insulin secretion. Nature 2004;432:226-30.

[65] El Ouaamari A, Baroukh N, Martens GA, Lebrun P, Pipeleers D, van Obberghen E. miR-375 targets 3'-phosphoinositide-dependent protein kinase-1 and regulates glucose-induced biological responses in pancreatic beta-cells. Diabetes 2008;57:2708-17.

[66] Tang X, Muniappan L, Tang G, Özcan S. Identification of glucose-regulated miRNAs from pancreatic $\beta$ cells reveals a role for miR-30d in insulin transcription. RNA 2009;15:287-93.

[67] Berry GJ, Budgeon LR, Cooper TK, Christensen ND, Waldner H. The type 1 diabetes resistance locus B10 Idd9.3 mediates impaired B-cell lymphopoiesis and implicates microRNA-34a in diabetes protection. Eur J Immunol 2014;44:1716-27.

[68] Lakhter AJ, Pratt RE, Moore RE, Doucette KK, Maier BF, DiMeglio LA, et al. Beta cell extracellular vesicle miR-21-5p cargo is increased in response to inflammatory cytokines and serves as a biomarker of type 1 diabetes. Diabetologia 2018;61:1124-34.

[69] Sekar D, Venugopal B, Sekar P, Ramalingam K. Role of microRNA 21 in diabetes and associated/related diseases. Gene 2016;582:14-8.

[70] Chang TC, Wentzel EA, Kent OA, Ramachandran K, Mullendore $\mathrm{M}$, Lee $\mathrm{KH}$, et al. Transactivation of miR-34a by p53 broadly influences gene expression and promotes apoptosis. Mol Cell 2007;26:745-52.

[71] Lovis P, Roggli E, Laybutt DR, Gattesco S, Yang JY, Widmann $\mathrm{C}$, et al. Alterations in microRNA expression contribute to fatty acid-induced pancreatic $\beta$-cell dysfunction. Diabetes 2008;57: 2728-36.

[72] Raver-Shapira N, Marciano E, Meiri E, Spector Y, Rosenfeld N, Moskovits N, et al. Transcriptional activation of miR-34a contributes to p53-mediated apoptosis. Mol Cell 2007;26:731-43.

[73] Tarasov V, Jung P, Verdoodt B, Lodygin D, Epanchintsev A, Menssen A, et al. Differential regulation of microRNAs by p53 revealed by massively parallel sequencing: miR-34a is a p53 target that induces apoptosis and G1-arrest. Cell Cycle 2007;6:1586-93.

[74] He A, Zhu L, Gupta N, Chang Y, Fang F. Overexpression of micro ribonucleic acid 29, highly up-regulated in diabetic rats, 
leads to insulin resistance in 3T3-L1 adipocytes. Mol Endocrinol 2007;21:2785-94.

[75] Arnold N, Koppula PR, Gul R, Luck C, Pulakat L. Regulation of cardiac expression of the diabetic marker microRNA miR-29. PLoS One 2014;9:e103284.

[76] Dooley J, Garcia-Perez JE, Sreenivasan J, Schlenner SM, Vangoitsenhoven R, Papadopoulou AS, et al. The microRNA-29 family dictates the balance between homeostatic and pathological glucose handling in diabetes and obesity. Diabetes 2016;65:53-61.

[77] Palmer JD, Soule BP, Simone BA, Zaorsky NG, Jin L, Simone NL. MicroRNA expression altered by diet: can food be medicinal? Ageing Res Rev 2014;17:16-24.

[78] Wu SY, Yan MD, Wu ATH, Yuan KS, Liu SH. Brown seaweed fucoidan inhibits cancer progression by dual regulation of mir-29c/ADAM12 and miR-17-5p/PTEN axes in human breast cancer cells. J Cancer 2016;7:2408-19.

[79] Yan MD, Yao CJ, Chow JM, Chang CL, Hwang PA, Chuang SE, et al. Fucoidan elevates microRNA-29b to regulate DNMT3BMTSS1 axis and inhibit EMT in human hepatocellular carcinoma cells. Mar Drugs 2015;13:6099-116.
[80] Yang Y, Ma Z, Yang G, Wan J, Li G, Du L, et al. Alginate oligosaccharide indirectly affects toll-like receptor signaling via the inhibition of microRNA-29b in aneurysm patients after endovascular aortic repair. Drug Des Devel Ther 2017;11:2565-79.

[81] Nunez Lopez YO, Garufi G, Seyhan AA. Altered levels of circulating cytokines and microRNAs in lean and obese individuals with prediabetes and type 2 diabetes. Mol Biosyst 2016;13:106-21.

[82] Massart J, Sjögren RJO, Lundell LS, Mudry JM, Franck N, O'Gorman DJ, et al. Altered miR-29 expression in type 2 diabetes influences glucose and lipid metabolism in skeletal muscle. Diabetes 2017;66: 1807-18.

[83] Chen HY, Zhong X, Huang XR, Meng XM, You Y, Chung AC, et al. MicroRNA-29b inhibits diabetic nephropathy in $\mathrm{db} / \mathrm{db}$ mice. Mol Ther 2014;22:842-53.

[84] Zhu Y, Tian F, Li H, Zhou Y, Lu J, Ge Q. Profiling maternal plasma microRNA expression in early pregnancy to predict gestational diabetes mellitus. Int J Gynaecol Obstet 2015;130:49-53.

[85] Jacovetti C, Rodriguez-Trejo A, Guay C, Sobel J, Gattesco S, Petrenko V, et al. MicroRNAs modulate core-clock gene expression in pancreatic islets during early postnatal life in rats. Diabetologia 2017;60:2011-20. 